Viewpoint

\title{
Adding apples and oranges: The monitoring of energy efficiency in the Dutch food industry
}

\author{
C.A. Ramírez*, K. Blok, M. Neelis, M. Patel \\ Department of Science, Technology and Society, Copernicus Institute, Utrecht University, Heidelberglaan 2, 3584 CS Utrecht, The Netherlands
}

Available online 12 March 2005

\begin{abstract}
This article develops indicators to monitor energy efficiency developments in the food and tobacco industry based on physical production data at the firm level provided by the statistics office of the Netherlands in a confidential basis. We measure energy efficiency by using an energy efficiency indicator which is the aggregate specific energy consumption. Our results show that the food and tobacco industry has improved their energy efficiency indicator in primary terms by about $1 \%$ per year (uncertainty range between 0.9 and 1.3). In terms of final energy, there has been a decrease on the indicator for final demand of fuels of about $1.8 \%$ p.a. while there has been no improvement in the indicator for final demand of electricity. The development in energy efficiency is coherent with the reported implementation rate of energy conservation projects. We conclude that the type and the quality of the data compiled by Statistics Netherlands for the food sector is sufficient to develop indicators as required by energy and climate policy.
\end{abstract}

(C) 2005 Elsevier Ltd. All rights reserved.

Keywords: Energy efficiency; Specific energy consumption; Food industry

\section{Introduction}

Decreasing $\mathrm{CO}_{2}$ emissions is arguably a main goal on the global environmental agenda. The potential ecological damage that could result from a shift in our current climate regime due to the increase in $\mathrm{CO}_{2}$ concentrations in the atmosphere has given rise to the necessity for policy making that could address the challenge of global warming. In this context, increasing energy efficiency has been pointed out as an important option for the abatement of greenhouse gases (i.e. two examples are the International Panel for Climate Change (IPCC) conclusion that technologies and practices for end use energy efficiency in buildings, transport and manufacturing industries account for more than half of the potential of greenhouse gas emission reduction in the 2010-2020 period (Metz et al., 2001) and the proposal from the European Commission (2004) for a directive in

\footnotetext{
${ }^{*}$ Corresponding author. Tel.: + 31302537639 ; fax: + 31302537601 .

E-mail address: c.a.ramirez@chem.uu.nl (A. Ramírez).
}

energy use efficiency). There is however a question that arises when policies are designed to improve energy efficiency and that is how to monitor changes in energy efficiency.

The ratio of energy use to amount of activity, hereafter called energy intensity, has been accepted as the quantitative measure against which energy efficiency development can be measured. ${ }^{1}$ Over the last decade, substantial research has been conducted on the problems and advantages related with the selection of activity measures (i.e. Freeman et al., 1997; Nanduri et al., 2002; Ross and Hwang, 1992; World Energy Council, 2001; Worrell et al., 1997). There is growing consensus that obtaining a clearer picture of energy efficiency improvements related to energy efficiency

\footnotetext{
${ }^{1}$ The main practical difference between the concept of energy intensity and energy efficiency is that while energy efficiency is inferred by looking at the technologies used in process and activities, energy intensity is inferred from data on activity and energy consumption (Schipper and Grubb, 2000).
} 
policies requires the use of indicators which filter out the influence of structural changes and relate the energy consumed to the physical output. In the case were the analysis is done at a high level of aggregation, economic measures of output (i.e. value added or GDP) are the most use measures of activity. This because of the daunting problem of representing output by a few welldefined products for which data on energy use and physical output are known (International Energy Agency (IEA), 2004).

Attempts to analyze energy efficiency trends in terms of energy per unit of physical output in the manufacturing sector at a lower level of disaggregation are found in an extensive body of literature, especially for energy intensive industries such as steel, pulp and paper or cement (i.e. Farla and Blok, 2000; Phylipsen et al., 1998; Ross and Feng, 1991). Non-energy intensive sectors, such as food or textiles, have drawn less attention and when studied, energy intensity trends are generally analyzed in terms of energy per unit of value added.

We are unaware of any study that has comprehensively examined the use of energy per unit of physical output in a heterogeneous, non-energy intensive manufacturing sector at a high level of aggregation. This article is a contribution to this deficiency. In it, we present findings from a detailed examination of the Dutch food and tobacco sector (NACE 15-16) for the period 1993-2001. Most important, we assess the feasibility of implementing the methodology and data sources used in this paper for monitoring future trends in energy intensity and the possibility of applying such methodology to other countries. It should be pointed out however, that in this paper we do not attempt to have an in-depth look at the factors that have affected the energy consumption in the food sector, leaving a formal treatment of the drivers behind the savings for another study. The structure of this paper is as follows. Section 2 briefly describes the food industry and its importance in the Dutch economy. A detailed description of the methodology and data used is given in Section 3 while main results are shown in Section 4. Finally, conclusions are drawn in Section 5.

\section{The food and tobacco industry}

In the European Union the food and tobacco sector (NACE 15-16) accounted for about $8 \%$ of the final energy demanded by the manufacturing sector in the year $2001^{2}$ (International Energy Agency (IEA), 2003). In the same year, with a total of 4885 companies (from which only 630 have more than 20 employees), the food and tobacco sector accounted in the Netherlands for about $9 \%$ of the final industrial energy demand, $15 \%$ of

\footnotetext{
${ }^{2}$ It does not include mining and agriculture.
}

Table 1

Statistical classification of economic activities in the European Community (NACE) for the food and tobacco sector at the 2-3 digit level of aggregation

\begin{tabular}{ll}
\hline NACE code & Description \\
\hline 15 & $\begin{array}{l}\text { Manufacture of food products and beverage } \\
\text { Production, processing and preserving of meat and } \\
\text { meat products }\end{array}$ \\
152 & $\begin{array}{l}\text { Processing and preserving of fish and fish products } \\
153\end{array}$ \\
154 & Processing and preserving of fruit and vegetables \\
155 & Manufacture of vegetable and animal oil and fats \\
156 & Manufacture of dairy products \\
157 & starch products \\
158 & Manufacture of prepared animal feeds \\
159 & Manufacture of other food products \\
16 & Manufacture of beverages \\
\hline
\end{tabular}

the industrial employment and $23 \%$ of the industrial value added. In terms of costs however, energy only amounts about $2 \%$ of the total production costs in the food sector (at the three and four digit level the range is $1-4 \%)$. The food and tobacco industry can be broken down into 10 three-digit NACE industry sectors (Table 1). Fig. 1 shows the primary energy demand of the food sector compared to the total Dutch manufacturing industry and its distribution by food sub-sector. ${ }^{3}$

\section{Methodology and data issues}

The analysis performed in this paper and the possibility to be implemented as a main source for analyzing energy efficiency developments in the food and tobacco industry depends greatly on the methodology used and the kind, availability and reliability of the data used. In this section we present an explanation of the method used to estimate energy efficiency improvement, the data used and the methodology applied to examine the effect of data uncertainty in the final results.

\subsection{Development of energy efficiency indicator}

The methodology used in this paper constructs on the work done by Phylipsen et al. $(1997,1998)$ and Farla (2000). In this paper, we seek to develop trends for technical energy efficiency by comparing trends in realized energy demand (as reported by the statistical office) and a reference energy use. We have selected as reference energy use the amount of energy that the food and tobacco sector would have used if no improvements in energy efficiency have occurred with respect to a base

\footnotetext{
${ }^{3}$ Primary energy was calculated according to the methodology described in Section 3.1.
} 


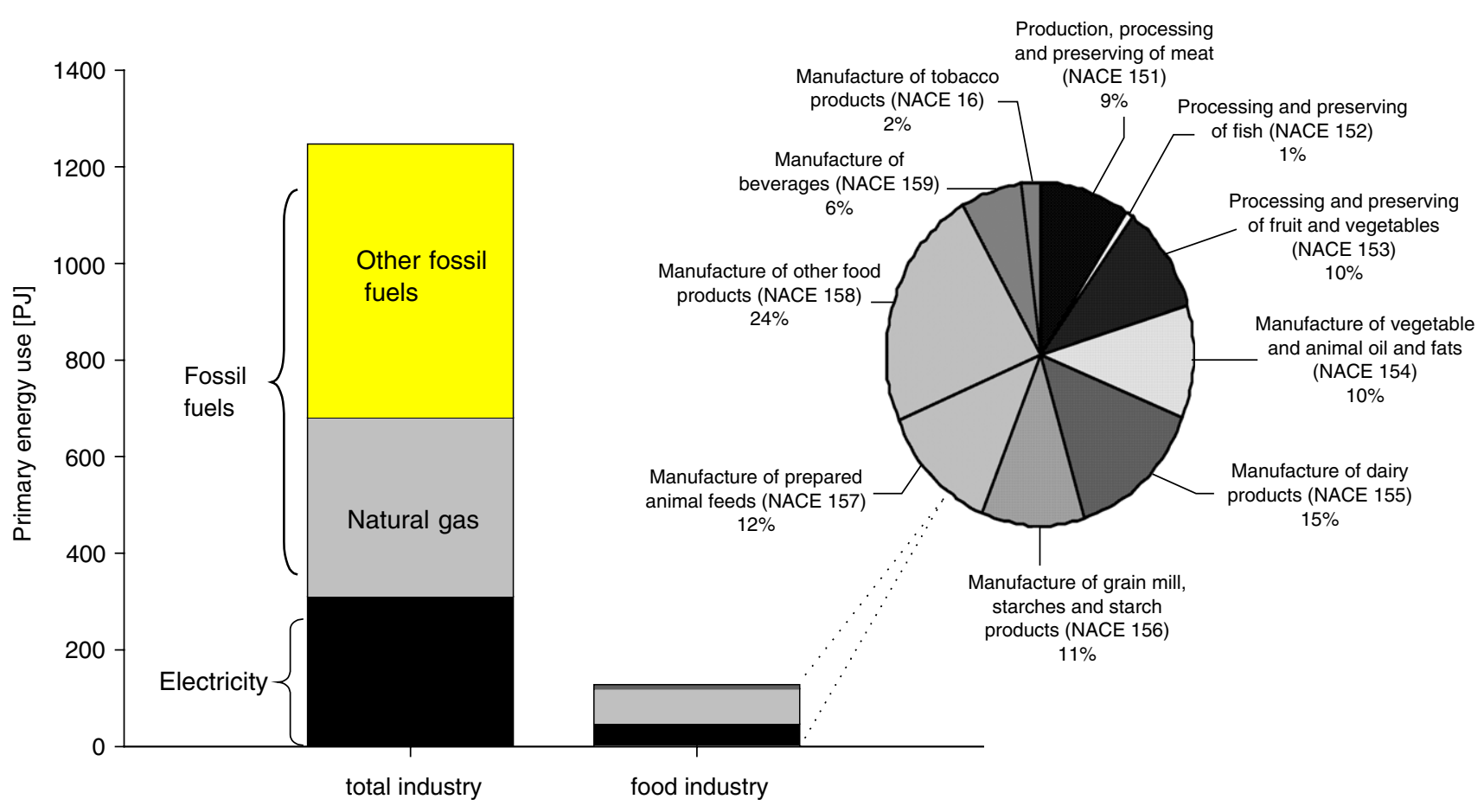

Fig. 1. Comparison of primary energy used by the Dutch food and tobacco industry, 2001.

year. We called this a frozen energy efficiency development. The frozen energy efficiency development is calculated based on two parameters: yearly physical production data and the amount of energy required in the base year to produce one physical unit of product. The latter parameter is generally referred to in the literature as specific energy consumption (SEC) or unit energy consumption. Note that the type of process, technology and efficiency level used to produce each product in the base year are reflected in the SEC value. Hence if for the base year, all products of a sector are accounted for and the SECs reflect their real energy requirements, the frozen energy demand equals the realized energy demand and thus the numeric value of the indicator would be one. Furthermore, because the frozen efficiency development is constructed by taking into account production developments in individual products, the resulting indicator already corrects for structural changes (e.g. shift of fluid milk to milk power). This procedure is in essence the same used by the Dutch Energy and Environmental Agency (Novem) to monitor improvements in energy efficiency as a consequence of the Long-Term Agreements (LTA). ${ }^{4}$ Eq. (1) shows the energy efficiency indicator by type of fuel.

\footnotetext{
${ }^{4}$ LTA are voluntary agreements between sectors of the economy (e.g., an industrial sector) and the Dutch government. The main goal of the LTA is to increase the energy efficiency of the sector by a given percentage in an established period of time. The information provided by the companies is given in a confidential basis. For more information see: http://www.mja.novem.nl
}

The base year used in this paper is $1995 .^{5}$

$\mathrm{EEI}_{j, k} \cong \frac{E_{j, k}}{\sum m_{i, k} \mathrm{SEC}_{i, j, 0}}$.

The energy efficiency indicator in primary energy $\left(\mathrm{EEI}_{p}\right)$ can then be calculated as:

$\mathrm{EEI}_{p, k}=\frac{E_{p, k}}{\sum m_{i, k} \cdot\left(S E C_{\mathrm{ref} i, j, 0} \cdot f_{j}\right)}=\frac{\sum E_{k, j} \cdot f_{j}}{\sum m_{i, k} \cdot\left(S E C_{\mathrm{ref} i, j, 0} \cdot f_{j}\right)}$

In which $k$ is the year of the analysis, with 0 denoting the base year, $j$ the type of fuel (i.e. electricity, fossil fuels/heat), $\mathrm{EEI}_{k, j}$ the energy efficiency indicator in year $k$ for fuel $j$ (dimensionless), $\mathrm{EEI}_{p, k}$ the primary energy efficiency indicator in year $k$ (dimensionless), $E_{j, k}$ the energy demand for fuel $j$, in year $k$ (e.g., in Terajoule); from energy statistics, $E_{p, k}$ the primary energy demand in year $k$ (in Terajoule), $m_{i, k}$ the physical production of product $i$ in year $k$ (e.g., in tonnes), SEC $_{i, j, 0}$ the energy use to produce product $i$, for fuel $j$, in the base year (e.g., in Gigajoules per tonne of final product) and $f_{j}$ the conversion factor from fuel $j$ for final use to primary energy.

\footnotetext{
${ }^{5}$ Results from our analysis have been used as an input for the calculations of total energy savings in the Netherlands made by the Energy Research Center of the Netherlands (ECN). We use 1995 as the base year because that is the base year used by ECN to calculate total energy savings in the Netherlands.
} 


\subsection{Energy data}

Energy data were taken from the annual energy balances for the food industry published in the energy-supply statistics part 1 . Energy balances for the food sector are published at the two-digit level of aggregation (NACE 15-16) and they cover all food companies in the Netherlands. System boundaries for the energy balances are shown in Fig. 2. The energy balance data account for the final use of fuel $\left(F_{3}\right){ }^{6}$ electricity $\left(E l_{4}\right)$, heat $\left(H_{4}\right)$ and non-energy use $(N)$. In this paper the analysis is based on data excluding nonenergy use. Data on primary energy consumption $\left(E_{p, k}\right)$ was calculated using final energy consumption values and tables for combine heat and power ${ }^{7}$ published in the energy-supply statistics part $2 .^{8}$ These tables show values on CHP total energy input $\left(F_{1}\right)$ and heat and electricity production $\left(E l_{2}\right.$ and $\left.\mathrm{H}_{2}\right)$. Primary energy $\left(E_{\mathrm{p}}\right)$ is calculated according to Eq. (3). We use as conversion factors from final energy to primary $\left(f_{j}\right) 1.05$ for oil products, 1.01 for natural gas, ${ }^{9} 2.5$ for electricity bought from the grid (reflecting a $40 \%$ conversion efficiency), ${ }^{10}$ and 1.11 for heat from boilers (reflecting a 90\% conversion efficiency). For steam produced from a CHP unit steam has been valued at $83 \%$ of its energy content. ${ }^{11}$

$E \mathrm{p}_{k}=\left(\left(F_{1_{k}}+F_{3_{k}}+\left(H_{1_{k}} / 0.9\right)\right) f_{\text {fuel }}\right)+\left(E l_{1_{k}} f_{\text {elect-grid }}\right)$.

To calculate the frozen efficiency development in terms of primary energy we take into account that already in 1995 (our base year), 32\% of the final electricity $\left(E_{4}\right)$ used in the food industry was produced by industrial cogeneration. We have estimated the

\footnotetext{
${ }^{6}$ Distinguishing between oil, natural gas and cokes.

${ }^{7} \mathrm{~A}$ combined heat and power unit (CHP) is a unit that produces both heat and electricity. The efficiency of these kinds of units is higher than when electricity and heat are produced separately.

${ }^{8}$ In the Dutch statistics if a CHP unit is operated in a joint venture between industry and energy sector, it is considered as an enterprise with main activity to produce heat and electricity, and thus its outputs are allocated to the energy sector and not the industrial sector. The values for CHP shown in the food balance are thus incomplete. The CHP balances published in part 2 of the energy statistics show the input and output of all CHP units by sector.

${ }^{9}$ These conversion efficiencies reflect losses in transportation and fuel conversion which are considered to be relatively small (e.g. Phylipsen et al., 1998). The Dutch Statistic Office has reported energy losses in transformation processes of about $7-10 \%$ for the oil sector and $1-5 \%$ in the gas sector. We took the upper limit.

${ }^{10} \mathrm{We}$ maintain the electricity generation efficiency constant in order to determine purely the effect of efficiency improvement on the energy demand side; otherwise effects of efficiency improvements in power generation (energy supply side) would also be included.

${ }^{11}$ We allocate fuel inputs of CHP plants on the basis of the exergy content of the products as described in (Phylipsen et al., 1998). We use an exergy factor for steam of 0.36 (Blok, 1991). In the year 1995, steam is valued at $83 \%$ of its energy content and electric efficiency is allocated to be $43 \%$.
}

electric efficiency for CHP in 1995 as $43 \%$. Thus, the average conversion factor for electricity ${ }_{\mathrm{CHP} \text {-powergrid to }}$ primary is calculated as 2.41 .

Finally, we have corrected the energy figures for climate influences using the Eurostat temperature correction method ${ }^{12}$ (assuming an average heating share of $20 \%$ based on data published in European community, 2003 and RIVM, 1995).

\subsection{Production data}

Since the goal of this study is not only to study the development in energy efficiency for the last few years but also develop a methodology that can be applied in the future, data sources for physical production were selected according to three conditions: (a) the data must be published annually for the Netherlands, (b) the data must be easily available, and (c) the source should be reliable. The main data source used in this study is the industrial production statistics Prodcom. Prodcom stands for Products of the European Community. It records physical volume and value of production of self-manufactured goods by using a uniform methodology throughout Europe. Within Prodcom, products are classified using the same coding as for the NACE classification of economic activities. The statistical unit is defined as an independent unit producing goods or services for third parties (Eurostat, 2001). The Prodcom survey covers all industrial enterprises with 20 or more employees. Using Prodcom has two main advantages. On the one hand, it covers more than 4000 detail products of the manufacturing sector, hence decreasing the number of data sources that are generally required for this kind of analysis. On the other hand, the international character of the survey implies that similar studies can be conducted in other countries. ${ }^{13}$

Within Prodcom, information related to industrial companies exists at different levels. At company level (covering all production sites of the same company) and at an aggregate level: covering all production sites within the same industrial branch. Data are published only at the aggregate level. However, due to CBS policy concerning the protection of the privacy of individual respondents, not all production data is actually reported in the aggregate values. In order to overcome this problem, we work with Prodcom data at the company level. Company data has been provided by the National

\footnotetext{
${ }^{12}$ The temperature correction method of Eurostat is based on the share of fuels used for heating purposes. Hence the temperature corrected energy $\left(E_{\mathrm{nt}}\right)$ is given by: $E_{\mathrm{nt}}=E_{\mathrm{ht}} / d_{\mathrm{t}}+E_{\mathrm{pt}}$, where $E_{\mathrm{ht}}$ is the energy used for heating purposes, $E_{\mathrm{pt}}$ is the energy used for nonheating purposes, and $d_{\mathrm{t}}=D_{\mathrm{t}} / D$, where $D_{\mathrm{t}}$ and $D$ are the actual and long-term degree days (Brook, 2001).

${ }^{13}$ For additional information on Prodcom see: http://forum.europa.eu.int/irc/dsis/bmethods/info/data/new/prodcom_questionnaire_en.pdf.
} 


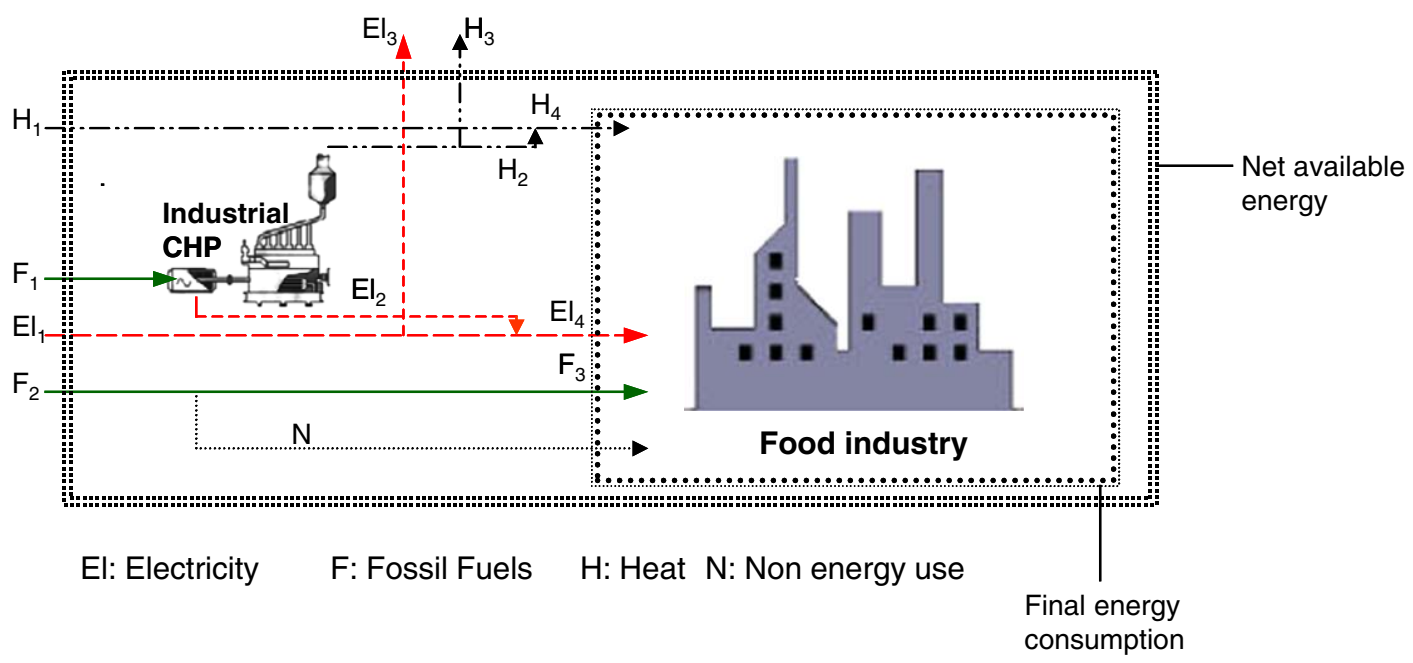

Fig. 2. System boundaries.

Statistical Office of the Netherlands (CBS) through their Center for Research of Economic Microdata (CEREM). There are however two main drawbacks. First, the data is only available from 1993 onwards and secondly, the data become available with a time lag. In the present setup this means a time lag of two years. Hence, the time frame used in this study is 1993-2001. The list of products and the methodology used to select them are described in Section 3.4.

We use Prodcom data for most products with the following exceptions:

- Meat sector: Because SEC data found in literature for the slaughtering of cattle, pig and poultry are based on dress carcass weight, we do not use Prodcom data which report production based on final weights but data provided by the Dutch Meat Board. Furthermore, since products produced during the processing of meat by-products (this is known as rendering) are not necessarily processed for sale (i.e. fallen stock or offal that are consider a danger to public health), we work with the amount of raw material processed (otherwise the influence of rendering in the energy consumption of the sector is underestimated). As there is a lack of statistical data on the total annual amount of raw material to be rendered, we assume that: (a) the total weight of raw material to be rendered per beast is typically: $198 \mathrm{~kg}$ (cattle), $21 \mathrm{~kg}$ (pig), $14 \mathrm{~kg}$ (sheep) and $0.7 \mathrm{~kg}$ (poultry) (Meat and Livestock Commission (MLC), 1998) and (b) fallen stock represents $10 \%$ of the tonnage processed annually (idem). ${ }^{14}$ Using data on the total number of slaughterings published by the Product Board for Livestock, Meat and eggs (PVE), the total amount of raw material to be rendered is calculated.

\footnotetext{
${ }^{14}$ In the Netherlands it is forbidden to bury fallen stock, all stock should be processed by rendering companies.
}

- Dairy sector: Prodcom values for dairy products show two problems: (a) strong fluctuations (it is the only sector studied which shows fluctuations of more than $100 \%$ from 1 year to another, for the other sectors typical fluctuations were at maximum of $30-40 \%$ from year to year) and (b) underestimation of the production of whole and semi-skimmed milk (this could be due to the fact that these products are not only sold as final products but are also used as intermediates and thus are not always reported within the sale statistics). Hence, we use production data reported by the Dutch Dairy Board (PZ).

- Cacao: Since we did not find SEC reference values for cacao products, instead of using production data for cacao products, we use as measure of activity the raw material processed (for which SEC figures are available). Raw material in this case is the total amount of cacao beans processed by the Netherlands. This data is published annually by CBS.

\subsection{Selection of products and specific energy consumption data (SEC)}

The selection of key products and of their SEC is a critical point for the analysis of the food sector. Prodcom distinguishes 413 different food product categories, from which the Netherlands reports on 335 . We look at each sub-sector of the food industry (i.e. dairy products, sugar, fruit and vegetables) and identified main processes and products which are important from an energy point of view. We made a literature survey to find SEC values. SECs were mainly gathered from open literature, however when data was unavailable from literature we calculated them based on energy and production data at the company level. For doing so, we select those companies that in our base year, 1995, 


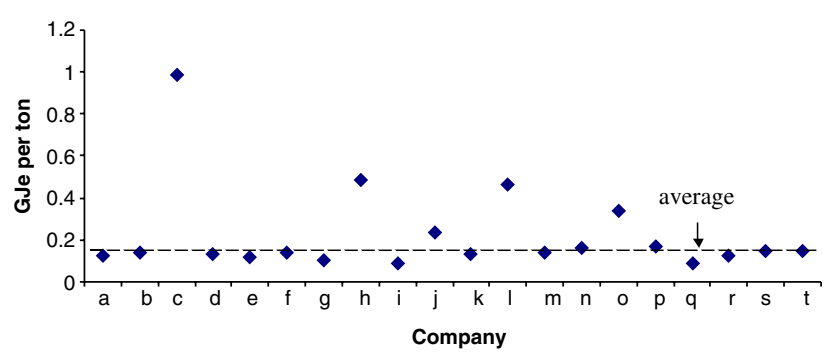

Fig. 3. Specific electricity consumption by Dutch companies that manufacture prepared food for farm animals in 1995.

only report one product in Prodcom (or use one main raw material) and using the energy data reported by the same company, ${ }^{15}$ we calculate their specific energy consumption as the ratio of the amount of energy use to the production (in physical terms). The SEC used in the analysis is determined as the average of the values found. As an example Fig. 3 shows the SEC for electricity for the manufacture of prepared food for farm animals. The products and SECs used in this study together with their sources are listed in Table 2. Due to confidentiality issues SECs that involve confidential information are only shown in terms of primary energy.

As explained in the methodology section, if all products were accounted for and their SEC were known, in the base year the frozen and realized energy use would be equal. We defined as coverage the proportion of the energy accounted for with the products selected respect to the total energy used by the sector in the base year. The coverage reached in this paper for the year 1995 is of about $81 \%$ for fuels/heat and $60 \%$ for electricity (we discuss the influence of these percentages in the results obtained in Section 4.3).

\subsection{Uncertainty analysis}

To quantitatively evaluate the uncertainty of our results we use what generally is referred to as a "Bayesian" or "subjective" characterization of probability. A Bayesian assessment of probability distributions can be interpreted as "the probability of an event is the degree of belief that the event will occur, given the observations, modeling results and theory currently available" (Moss and Scheiner, 2000). The procedure is as follows: first we identify the main sources of uncertainty, second we represent these uncertain elements as probability density functions PDFs ${ }^{16}$ (see Fig.

\footnotetext{
${ }^{15}$ Energy at the company level is also available form CEREM on a confidential basis. The energy panel contains information that makes it possible to calculate each company's average electricity, fuel and heat demand.

${ }^{16}$ PDFs are a common way to present results. Unlike error bars, which only give a range in which the solution should fall, PDFs attach a likelihood to each possible value. A PDF represent the density of probability so that a parameter $p$ takes a value $f\left(p_{1}\right)$ if the probability
}

4) and thirdly the inputs are combined to generate the PDF of the output. The program used to generate the PDF of the output is Crystal Ball 2000, the number of trials was set to 100,000 and the certainty range to $95 \%$.

As sources of uncertainty we identified the following parameters: SECs for fuel and electricity, and the production and energy data provided by the statistical offices and industrial associations. For the parameters for which the range and the most likely value were known (from literature or national surveys) we use a triangular distribution. ${ }^{17}$ For those parameters for which there was only information available about the range of values but not about the most representative value for the Netherlands or the SEC data was not gathered in the base year, a uniform distribution is used. ${ }^{18}$ In this case, the range is made taken into account the most extreme values found in literature for European countries in the 1990s. When historical data was available we use Crystal Ball to fit the PDF to the data. In Appendix A we show the different PDFs used in this paper for the SECs values.

The method selected to encode the PDFs of the energy and production data is the fixed value method. ${ }^{19}$ Thus, for the energy data we use a triangular distribution with an uncertainty range of 5\% (although uncertainty in the energy balances has been estimated as low as $1 \%$ (Boonekamp et al., 2001), we found that fluctuations in energy data oscillate about 5\%). For production data from industrial associations we use a triangular distribution with an uncertainty of $\pm 5 \%$.

For Prodcom data we consider that:

- There is a systematic error introduced by the fact that the answer response to the survey is not $100 \%$;

(footnote continued)

of the parameter value lying between $p_{1}$ and $p_{1}+\delta p$ is $f\left(p_{1}\right) \delta p$, where $\delta p$ is a small increment of $p$. A PDF can take a number of standard forms i.e. uniform, normal, log normal, triangular, etc.

${ }^{17}$ In a bell shape or a triangular distribution we assume that the value is more likely to be near the mean than far away. We selected a triangular distribution because its "apparently arbitrary shape and sharp corners are a convenient way to telegraph the message that the detail of the shape of the distribution are not precisely known. This may help to prevent over interpretation of results or a false sense of confidence" (Morgan and Henrion, 1990, p. 96).

${ }^{18}$ In a uniform distribution we assume that there are equal probabilities that a value would be close to the mean than far away. This distribution is considered appropriate when it is possible to identify a range of possible values but is not possible to decide which value is more likely to occur.

${ }^{19}$ There are three main methods to encode distributions. Fixed values methods (the probability that the quantity lies in a specific range of values is assessed), fixed probability (values of the quantity that bound specified fractiles or confidence intervals are assessed; i.e. a typical question could be: give a value $x$ such that the unknown quantity has a $25 \%$ chance of being less than $x$ ), bisection or intersection method (in it the median is assessed first, followed by the median of each quartile, the median of each octile and so on) (Morgan and Henrion, 1990). 
therefore the survey tends to underestimate the production figures (as minimum the survey should report $90 \%$ of the production). Thus we assumed that the triangular PDF is skewed to the right (positively skewed) with ranges of -5 to $+10 \%$.

- The survey only accounts for companies with more than 20 employees. This can increase the problem of underestimation for those products which are produced to a large extent in companies with less than 20 employees. In some cases it may not even possible to reach the $90 \%$ of the production. From the products selected in this paper the following products have been listed as problematic in a confidential evaluation made by the CBS on the Prodcom survey (Bontriderde Steur and Stroeks, 2003): sausages not of liver (Prodcom 15.13.12.15), frozen vegetables and mixtures of vegetables (Prodcom 15.33.14.40), sweet biscuits (Prodcom 15.82.12.53), waffles and wafers (Prodcom 15.82.12.59), fodder for the feeding of pets (Prodcom 15.72.10.30 \& 15.72.10.50). For these products we have used triangular PDFs with ranges of $-5 \%$ to $+20 \%$.

- There is a difference in the quality of the Prodcom data. It is estimated that data in 1993 and 1994 is less reliable than the data for the period 1995-2001 (1993 was the first year the survey was done; hence 1993 and 1994 have low response), we reflected this by doubling the uncertainty range of Prodcom data for the years 1993-1994.

\section{Results}

Fig. 5 shows the trends obtained for the primary energy efficiency indicator $\left(\mathrm{EEI}_{p}\right)$ and EEI by fuel (based on final energy use) for the food and tobacco industry as well as the frozen and realized energy use. Uncertainty ranges varies between $2 \%$ and $5 \%$ for $\mathrm{EEI}_{p}$ and between $3 \%$ and $6 \%$ for EEI for fuels and electricity ( $95 \%$ confidence). We found cumulative savings, in terms of primary energy, of about 11 PJ (uncertainty range 8-14 PJ) for the period 1993-2001. This savings have been mainly due to improvement efficiency of fossil fuels/heat per unit of product (EEI fuels has decreased by about $15 \%$ (range $-8 \% ;+19 \%$ ) while no improvement in electricity efficiency has been observed. Furthermore, we calculate that in addition, increased penetration of CHP in the food and tobacco industry since 1993 has saved about $2.8 \mathrm{PJ} \pm 5 \%$ primary energy in the Netherlands.

Next we explore our results in terms of projected savings, the sensitivity of the uncertainty ranges, the number of products analyzed and the fitness of SEC found in literature respect to the Dutch situation.

\subsection{Confrontation of projected savings with total savings}

To evaluate the plausibility of the savings shown by the $\mathrm{EEI}_{p}$ we have looked at (a) the penetration of CHP and (b) whether there has been new technologies or changes in process during the period that would demand lower fuel/heat consumption. An inventory of energy saving technologies was done using information published in the Long Term Agreements and data from three Dutch subsidy programs: TIEB (tenders industrial energy savings), BSET (subsidies for energy conservation techniques) and the Dutch subsidies program for project demonstration.

Each of these programs publishes a description of the different projects by year and sector and it specifies energy savings by fuel. We only account for projects that have been implemented in the period 1995-2001 (when it was not specified in the description if and when the project has been implemented, we called the companies in charge). The kind of projects and savings are shown in Table 3. These projects alone have saved about 3780 TJ of primary energy. These savings together with increased CHP penetration are already able to explain about $80 \%$ of the change in the $\mathrm{EEI}_{p}$ between both years (Fig. 6). We also found that savings on electricity have not been very important. Furthermore, $60 \%$ of the savings due to energy saving technologies is due to technologies implemented after 1999. This corroborates the strong decrease shown by the indicator in Fig. 5 and thus it is a confirmation that the indicator is sensitive enough to reflect important changes.

\subsection{Sensitivity of the uncertainty ranges}

Fig. 5 shows the results of the uncertainty analysis as described in the methodology. In order to understand the uncertainty ranges, we first look at the influence of the uncertainties in each parameter (production, energy and SEC) by running calculations where only one of the parameters at the time contribute to the final uncertainty. Not surprisingly we found that in 1993 and 1994 uncertainties in production data had a higher influence than in 2001. This because as explained in Section 3.5, uncertainties ranges of Prodcom data were doubled (compared with the years 1995-2001) to account for a low response rate. ${ }^{20}$ When this is not the case, uncertainties in SEC gain relevance.

We have then looked whether the results are dependent on the probability function assigned to the SECs. To this end, we have changed all SEC fuel and electricity PDFs to uniform distributions. We found that at the level of certainty we are working with (95\%), changing the PDF only affect the uncertainty range

\footnotetext{
${ }^{20}$ As a consequence of 1993 and 1994 being the first years where the survey was conducted.
} 







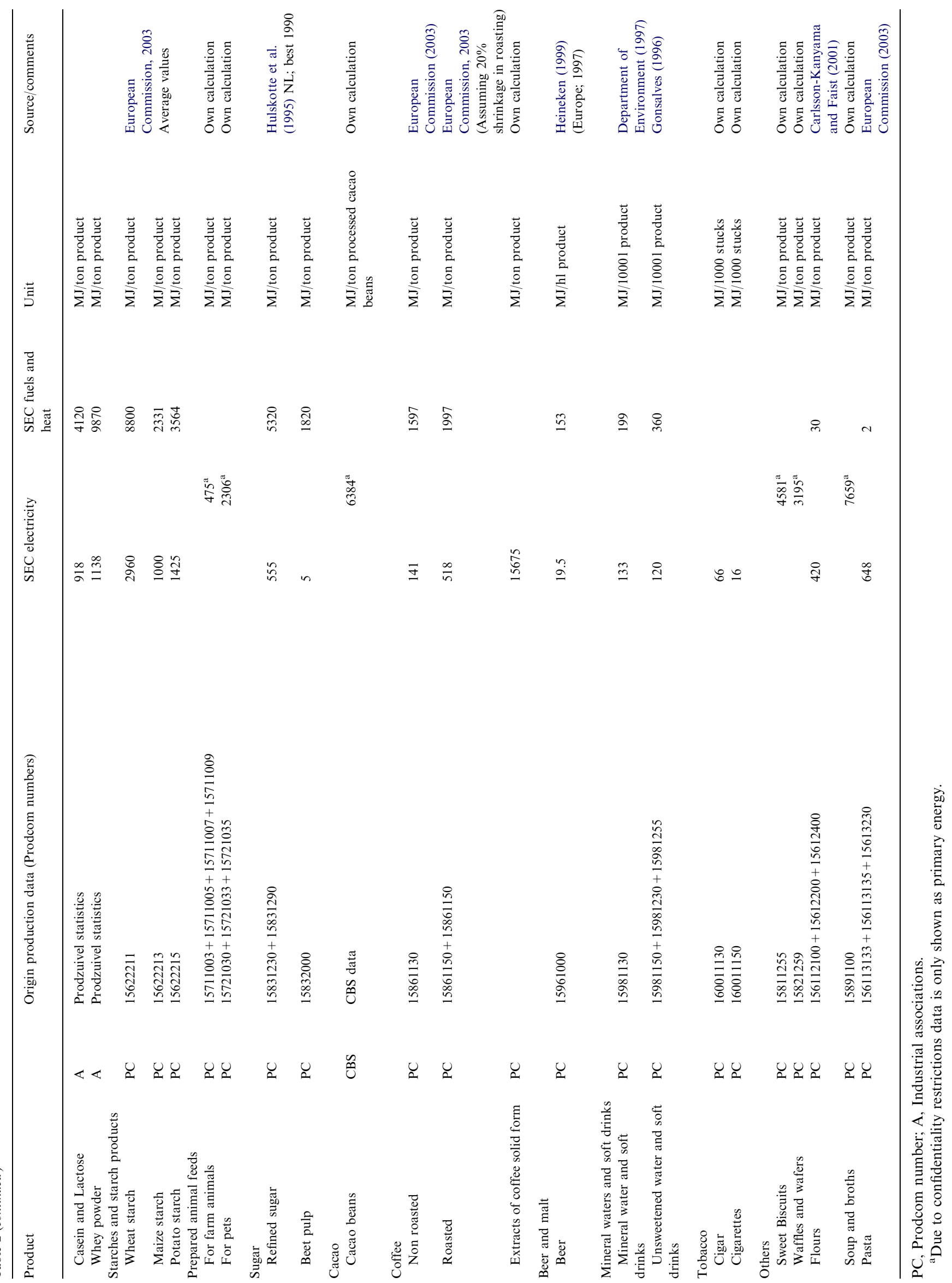


when the PDF of the original outcome distribution is highly asymmetrical. This shows that the results are dependent on uncertainties in the shape of the SEC distributions.

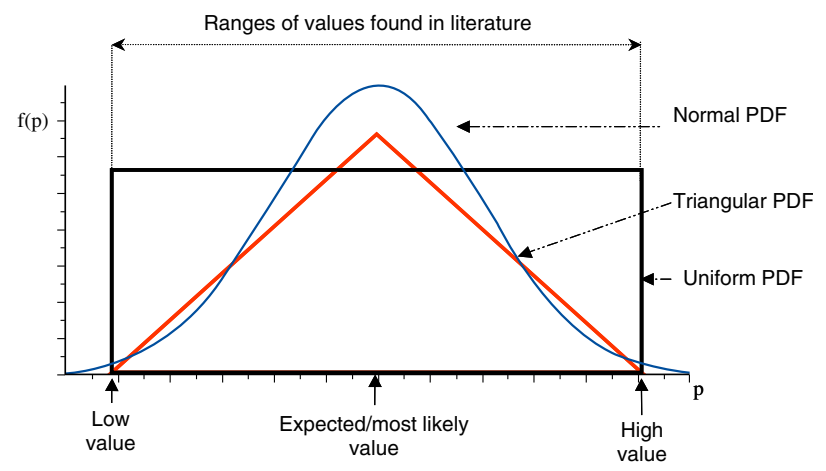

Fig. 4. Schematic illustration of probability density functions for parameter $p$.
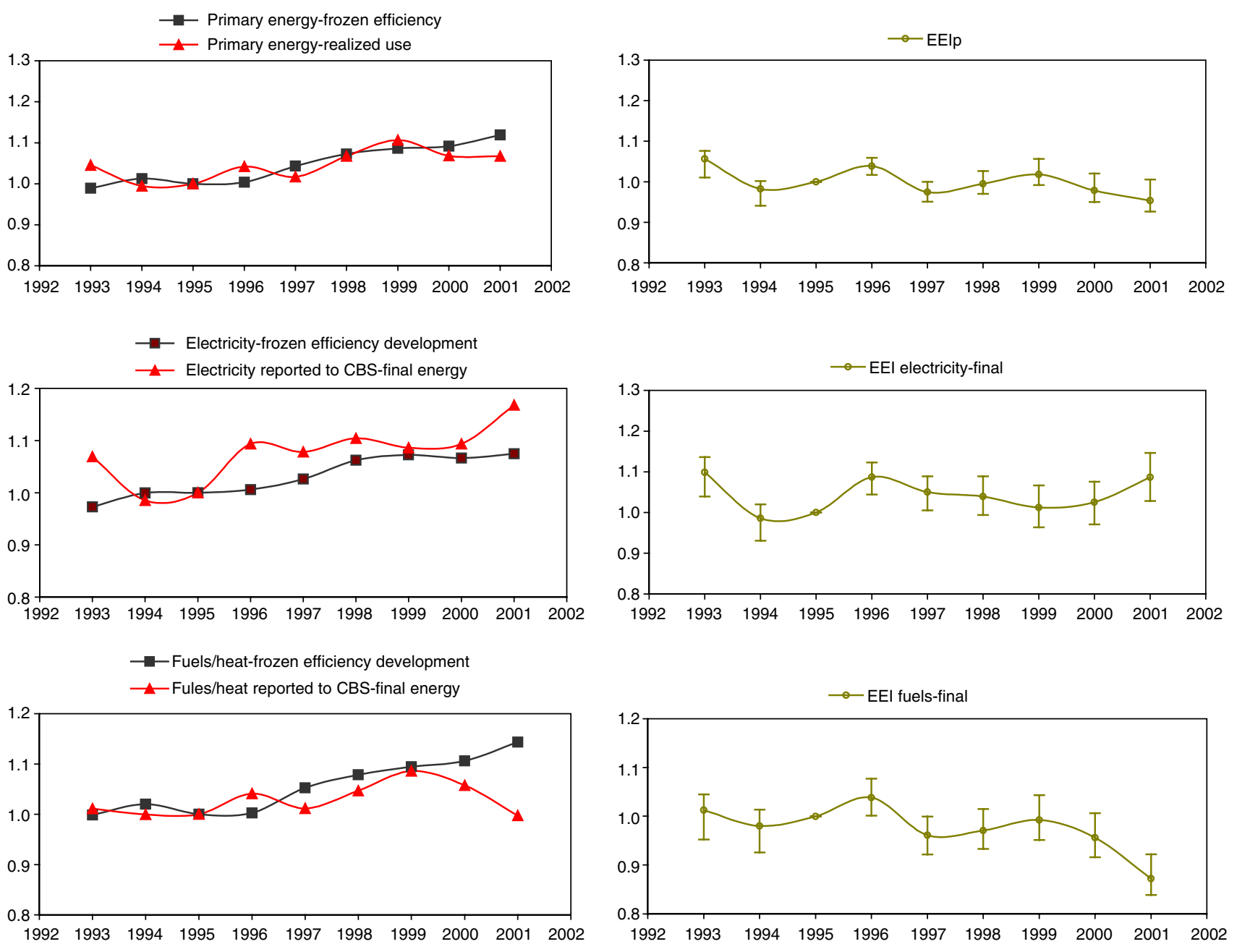

Fig. 5. Reference energy use, realized energy use and energy efficiency indicator for primary energy, final fuels/heat, electricity in the Dutch food industry.

Finally, we have taken into consideration that SECs values for fuel and electricity are not always independent. Crystal Ball generates random numbers for each input parameter without regard to how random numbers are generated for other assumptions. This procedure does not affect our results for individual fuels but it does for primary energy. Since there is a lack of data to evaluate the dependence between SECs for fuel and electricity, we have assumed three cases: (i) there is a 'negative strong' dependence between electricity and fuel use, (ii) there is a 'negative weak' correlation and, (iii) there is no correlation. The first case applies especially to products where most of the energy is used for concentration/evaporation (i.e. powder products). Here high use of fuels/heat is generally accompanied by a lower demand of electricity (i.e. evaporation with thermal vapor recompression demands larger amounts of heat and almost no electricity, while evaporation with mechanical vapor recompression demands the opposite). No correlation applies to products that are for instance frozen (since the amounts of heat used during

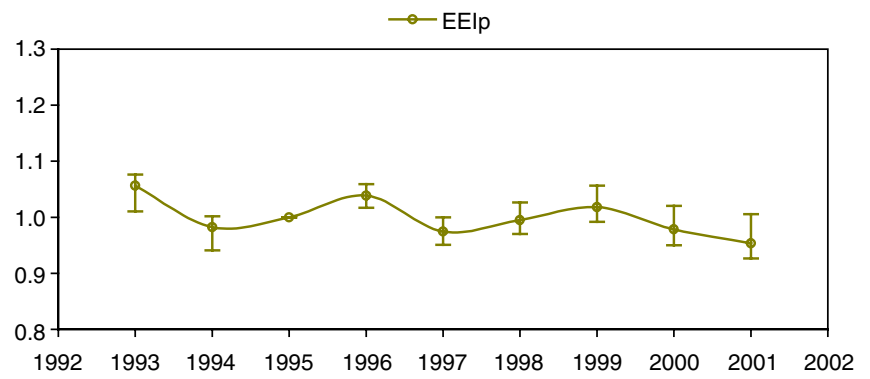


Table 3

New energy saving processes/technologies in the food and tobacco industry for the period 1995/2001

\begin{tabular}{|c|c|c|}
\hline Kind of saving technique/project & Number of projects & Primary energy savings $(\mathrm{TJ})$ \\
\hline Membrane filtration & 3 & 16 \\
\hline Heat recovery/reuse & 62 & 527 \\
\hline Batch to continuous process & 3 & 52 \\
\hline Retrofit/installation cleaning in place & 17 & 43 \\
\hline Retrofit/optimization of drying & 11 & 43 \\
\hline Regenerative thermic oxidation & 2 & 278 \\
\hline Retrofit/optimization of evaporators (includes installation of MVR) & 18 & 175 \\
\hline Increase capacity/higher load factors & 9 & 206 \\
\hline Installation/optimization isolation & 17 & 11 \\
\hline Implementation biogas/solar energy & 22 & 80 \\
\hline Use of less water/recirculation water/water at less temperature & 19 & 67 \\
\hline Automation/knowledge system & 13 & 119 \\
\hline Increase efficiency boilers/rational use boilers & 18 & 59 \\
\hline Optimization steam use & 2 & 4 \\
\hline Optimization cooling & 51 & 41 \\
\hline Optimization compress air & 22 & 13 \\
\hline Change in pasteurization conditions & 6 & 5 \\
\hline Optimization/retrofit electric motors, pumps ventilators, lightning & 40 & 21 \\
\hline Increase efficiency of vacuum pumps/system & 6 & 131 \\
\hline Installation/retrofit/optimization condensers & 8 & 48 \\
\hline Installation/retrofit economizers after boiler & 7 & 8 \\
\hline Optimization fuel use/change on fuel & 5 & 37 \\
\hline Optimization production process & 23 & 282 \\
\hline Energy management and good housekeeping & 179 & 264 \\
\hline Introduction new production lines/closing energy inefficient lines & 8 & 11 \\
\hline $\begin{array}{l}\text { Other (i.e. installation of sector specific techniques or processes such as butter } \\
\text { deodorization (packed column), use of less energy intensive packaging, etc.) }\end{array}$ & 195 & 1239 \\
\hline Total & 766 & 3780 \\
\hline
\end{tabular}

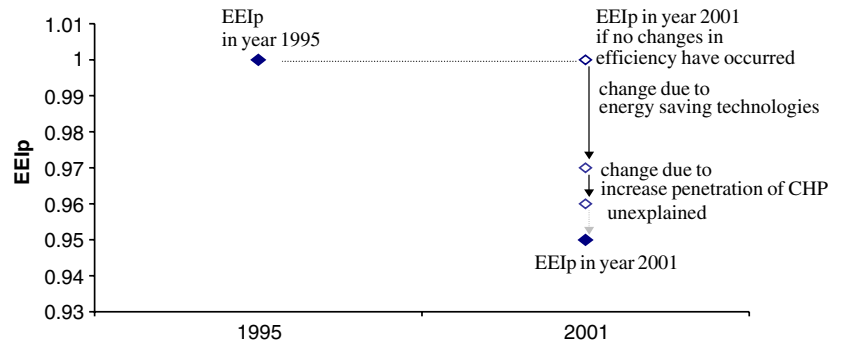

Fig. 6. Causes of changes in the EEI $p$ for the period 1995-2001.

processing is not affected by the amount of electricity used for refrigeration). When computing uncertainties for the $\mathrm{EEI}_{p}$, the correlations limit the way as the random numbers for each parameter are selected (i.e. in a negative correlation, if the computer selects a high SEC for fuel, it will then select a low SEC for electricity). The correlation factors are: $-0.7,-0.3$ and 0 , respectively. Note that the correlation factors used only reflect our qualitative understanding of the relations. We found that as expected including the correlations in the simulation decreases the skewness of the distributions of the outcome (i.e. in 2001 the PDF for the $\mathrm{EEI}_{p}$ show an skewness of 1.465 without the correlations and with the correlations is 1.038) and decreases their range of uncertainty, although only marginally (by about $0.5 \%$ ). Since for the purpose of the paper the shape of the outcome PDF is not important, the overall impact of introducing the correlations is weak and we consider our results as robust on this point.

\subsection{Coverage}

One question we have not tackled yet is how representative our results are for the behavior displayed by the whole food industry. As pointed out in Section 3, we do not take into account all products when developing EEIs (the 49 product categories shown in Table 2 account for $51 \%$ of the Prodcom food categories and, the coverage obtained in the base year is of $81 \%$ for fuels and $60 \%$ for electricity). There are two main reasons for it. First of all, specific energy consumption data is not available for every individual product. Secondly, if the methodology is to be used in a regular and consistent basis, the burden of data gathering and evaluation of data quality should be minimized. Therefore, there must be some kind of tradeoff between the number and the representativity of characteristics accounted for.

In order to assess whether or not the product mix studied in this paper is representative, we have 


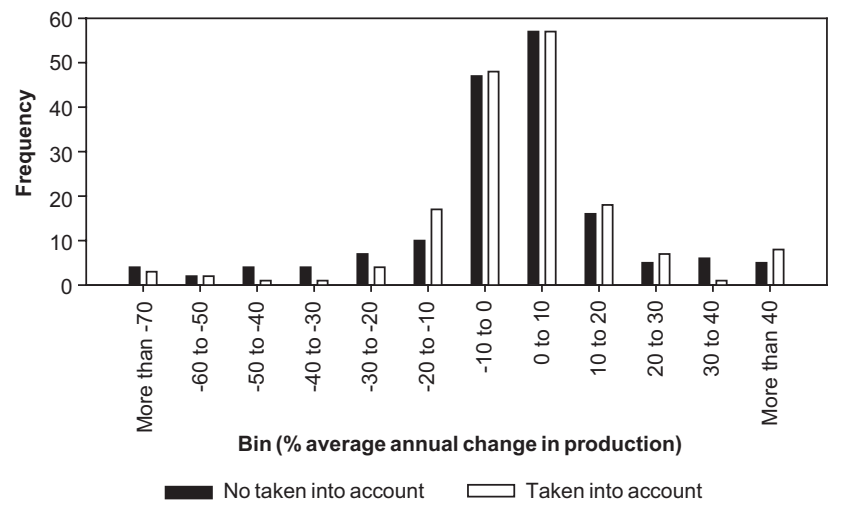

Fig. 7. Histograms for annual change in production when developing energy efficiency indicators.

calculated the average annual change in physical production for the 335 Prodcom products reported for the period 1993-2001. We compare the distribution of the products taken into account in this study against those left out. Fig. 7 depicts the frequency distribution of both groups. As shown, both groups exhibit similar behaviors. Thus, we are confident that the products selected reflect important structural changes in the food industry (i.e. decrease in energy consumption as a consequence of decreasing production of relatively more energy intensive products).

\subsection{Comparison with data from the LTAs}

So far we have analyzed the uncertainty level generated by data, and the representativity of the products selected, there is however an additional issue: the indicators depicted in Fig. 5 have been calculated based on 49 SEC values (Table 2) which were gathered from open literature and own calculations. The question then arises whether the trends based on such SECs reflect the "real" frozen efficiency behavior of the Dutch food and tobacco industry. One way to verify this is to compare the frozen efficiency energy use developed in this study with that reported by Novem (which is based on the LTA). Since the LTA data are based on confidential data provided by the industries, the frozen efficiency energy demand of the LTA should reflect the real production mix of the Dutch industry and will allow us to assess how well our indicators fit the Dutch situation. Note that the comparison can only be done for primary energy because it is the only information published by the Dutch Energy and Environmental Agency (Novem) (2001a-j).

Fig. 8 shows the trends reported by Novem and two trends developed in this study for the food sector: (a) if only the LTA industries which signed the covenant were taken into account and (b) if LTA industries and three

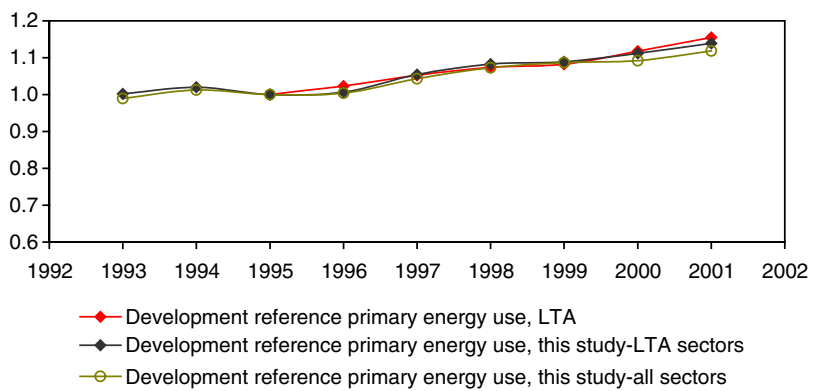

Fig. 8. Primary frozen energy efficiency in the food and tobacco industry according to this study and according to the LTA.

additional sectors plus some food products are included (this is the result shown in Fig. 5). Note that since not all sectors had LTAs before 1995, the LTA for the whole food and tobacco sector is only given for 1995 onwards. We found that our values differ from LTA values by a maximum of $4 \%$. For comparison, Fig. 9 shows the indexes for those industries with a LTA. From Figs. 8 and 9, we conclude that the indexes developed in this study accurately reflect the frozen energy efficiency behavior of the Dutch food and tobacco industry.

\section{Conclusion}

Much energy and environmental policy is based on prediction, prediction relies on modeling which in turn relies on indicators that accurately reflect "real" developments. In the energy debate it seems to be accepted that wherever possible, energy efficiency indicators should be used which are based on physical measures of output. In the past this kind of analysis has been mainly done for energy intensive sectors such as steel or aluminum and was in fact the basis of the first generation of the Long Term Agreements applied in the Netherlands. In this paper we have shown that it is indeed feasible to monitor energy efficiency developments in the food industry based on physical production data at the company level and according to our uncertainty analysis and comparison with other data the results obtained are reliable. This is an important finding since it means that energy efficiency in the food sector can be monitored by an energy agency without needing to implement a task force that depends on company reporting which is done with the sole purpose of monitoring developments in energy efficiency. This is a very promising outcome not only because it is rather likely that similar analysis can also be conducted for other non-energy intensive industries in the Netherlands, it also gives rise to hopes that similar analysis for non-energy intensive sectors can be conducted for other 

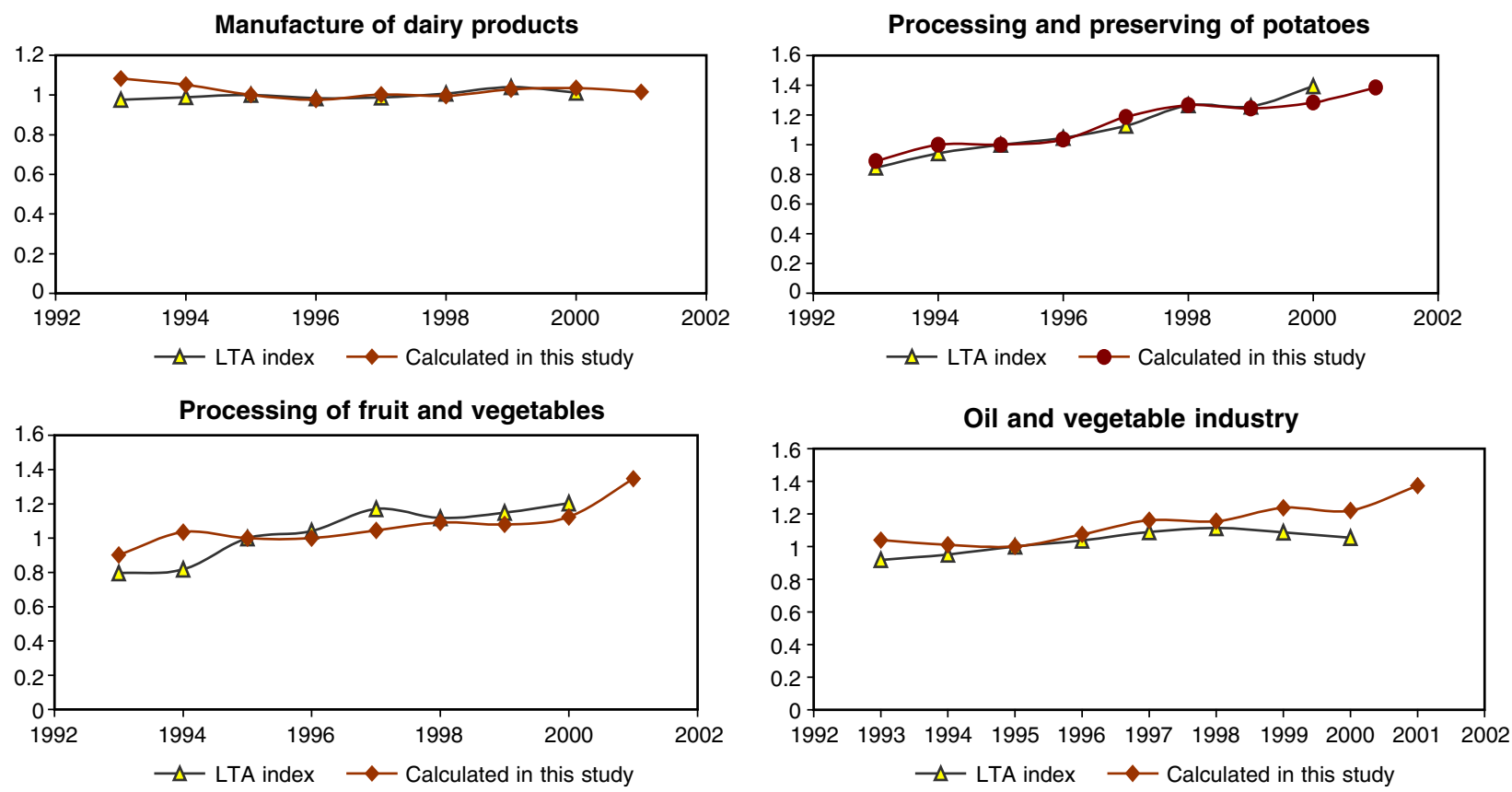

Manufacture of cocoa



Processing of coffee

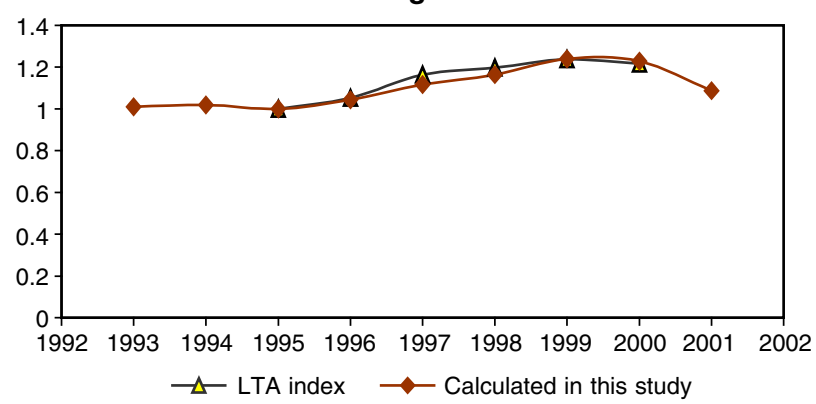

Production, processing and preserving of meat
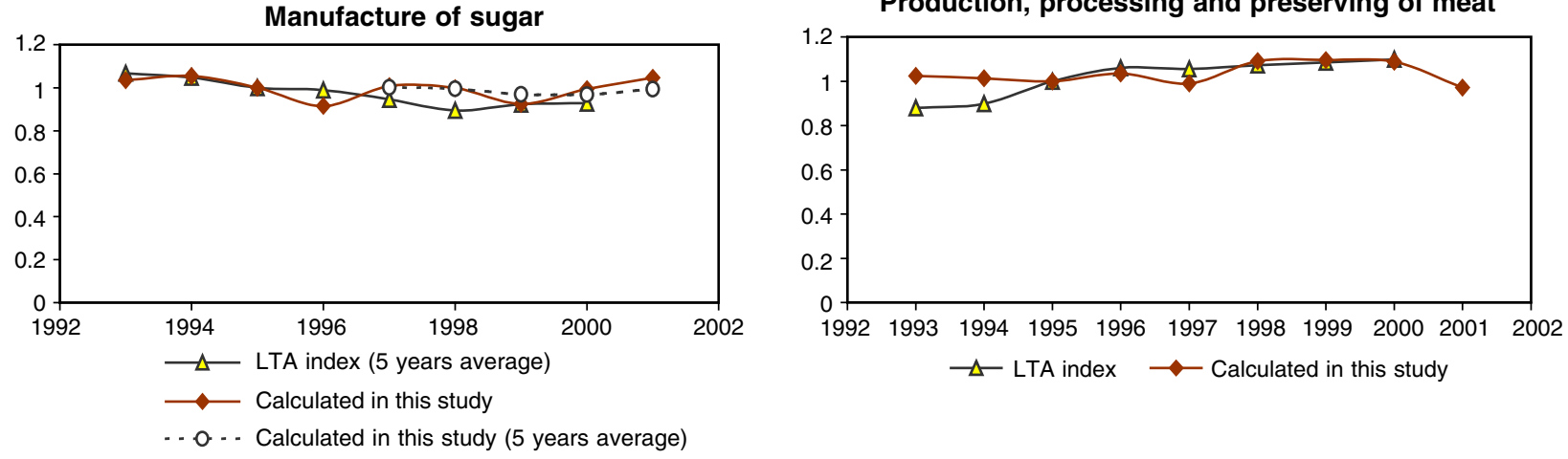

Production of mineral water and soft drinks
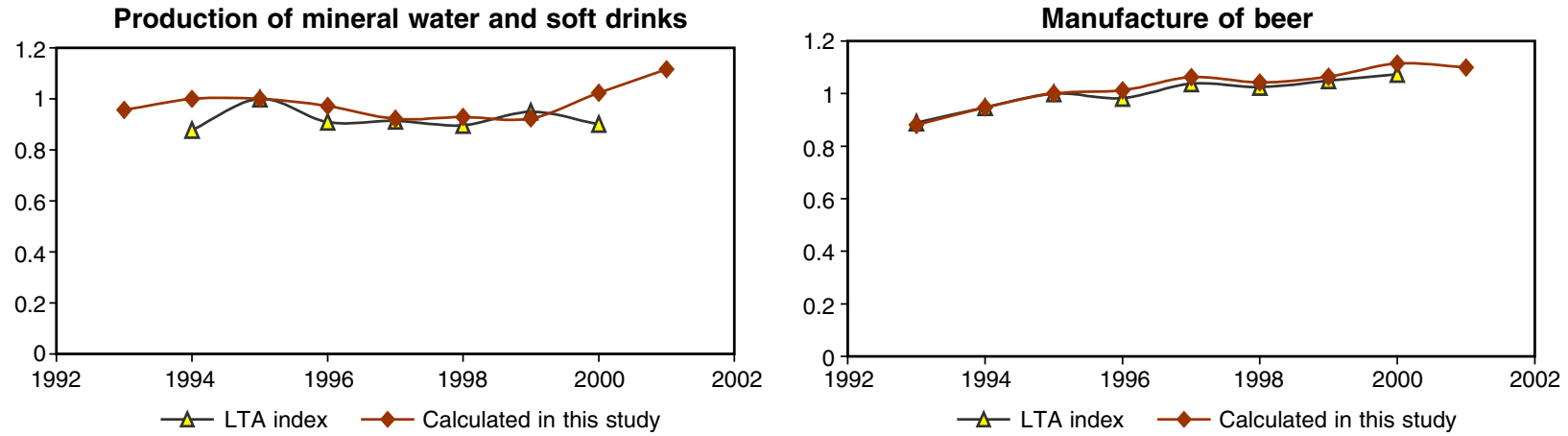

Fig. 9. Primary frozen energy efficiency development by branch in the food industry according to this study and the LTA (indexed to 1995). 
countries. The sole condition is that production data can be made available (for example in a confidential basis as in the Netherlands).

\section{Acknowledgements}

The authors are grateful to Mr. Wouter Tinbergen and $\mathrm{Mr}$. Theo Klinkers from the National Statistical Office of the Netherlands (CBS) for their help on gathering and interpreting the data used in this paper; to Prof. Dr. Bert Balk and the people from CEREM that made possible the access to firm level data and to
Dr. Jeroen van der Sluijs (Utrecht University) for his help on the development of the uncertainty analysis.

This work was partly funded by the Platform Monitoring Energy Savings via the Policy Studies unit of the Energy Research Centre of the Netherlands $(\mathrm{ECN})$. Any mistakes remain the responsibility of the Authors.

\section{Appendix A}

The different PDFs used in this paper for the SECs values (Table 4).

Table 4

Probability distribution functions used in this paper

\begin{tabular}{|c|c|c|}
\hline \multirow[t]{2}{*}{ Parameter/product } & \multicolumn{2}{|l|}{ PDF attributes } \\
\hline & SEC fuels & SEC electricity \\
\hline Beef + Sheep & Triangular (4833-5907) & Triangular $(150-500)$ \\
\hline Pig & $\log$ normal $\sigma=0.157$ & $\log$ normal $\sigma=0.65$ \\
\hline Poultry & Log normal $\sigma=2.77$ & $\log$ normal $\sigma=2.37$ \\
\hline Processed & Triangular (2555-4340) & Triangular (490-1017) \\
\hline Rendering & Triangular (1674-3000) & Triangular (100-350) \\
\hline Fresh (fillets) & Triangular (6-7) & Triangular $(90-170)$ \\
\hline Frozen & Triangular (6-7] & Triangular (520-810) \\
\hline Prepared or preserved fish & Triangular (900-1260) & Triangular (337-627) \\
\hline Smoked and dried & Triangular (1869-2280) & Triangular $(840-1560)$ \\
\hline Fish meal & Triangular $(5580-6820)$ & Triangular $(547-821)$ \\
\hline Potatoes products & Triangular $(3220-3930)$ & Triangular (621-932) \\
\hline Unconcentrate Juice & Uniform (610-1100) & Uniform $(200-400)$ \\
\hline Tomato juice & Triangular $(3500-5200)$ & Triangular $(100-450)$ \\
\hline Frozen vegetables and fruits & Triangular (1500-2000) & Triangular (371-1325) \\
\hline Preserved mushrooms & Uniform (2198-3155) & Uniform (314-707) \\
\hline Vegetables preserved by vinegar & Uniform (900-1503) & Uniform (275-590) \\
\hline Tomato ketchup & Triangular $(1400-1500)$ & Triangular (267-497) \\
\hline Jams and marmalade & Uniform (750-2550) & Uniform (343-637) \\
\hline Dried vegetables and fruits & Uniform (4050-6990) & Uniform (1350-1950) \\
\hline Crude oil + Refined oil & Triangular (3008-5530) & Triangular (73-135) \\
\hline Milk and fermented products & $\log$ normal $\sigma=0.63$ & Log normal $\sigma=0.63$ \\
\hline Butter & Triangular (1156-1414) & Triangular (411-563) \\
\hline Milk powder & $\log$ normal $\sigma=2.44$ & $\log$ normal $\sigma=2.24$ \\
\hline Condensed milk & Triangular (1742-2130) & Triangular (265-325) \\
\hline Cheese & Log normal $\sigma=1.62$ & Log normal $\sigma=1.82$ \\
\hline Casein and Lactose & $\log$ normal $(\sigma=1.76)$ & Log normal $(\sigma=1.94)$ \\
\hline Whey powder & Triangular (6910-12831) & Triangular (8080-15000) \\
\hline Wheat starch & Uniform (6768-10998) & Uniform $(1692-4230)$ \\
\hline Maize starch & Uniform (1332-3330) & Uniform (666-1332) \\
\hline Potato starch & Uniform (1188-5940) & Uniform (950-1901) \\
\hline Farm animal & Log normal $\sigma=0.608$ & Log normal $\sigma=0.1428$ \\
\hline Pets & Triangular (1144-2900) & Triangular (31-65) \\
\hline Refined sugar & Triangular (5024-6699) & Triangular (202-824) \\
\hline Cacao beans & Triangular (3391-4150) & Triangular $(947-1150)$ \\
\hline Non roasted coffee & Triangular $(130-190)$ & Triangular (112-169) \\
\hline Roasted coffee & Triangular (1600-2410) & Triangular (415-622) \\
\hline Extracts of coffee solid form & Triangular (8910-14000) & Triangular (10710-13000) \\
\hline Beer & Triangular (1379-1680) & Triangular $(176-210)$ \\
\hline Mineral water and soft drinks & Triangular $(1800-2190)$ & Triangular (106-160) \\
\hline Unsweetened water and soft drinks & Triangular $(290-435)$ & Triangular $(97-140)$ \\
\hline Cigar & Triangular (0.019-0.061) & Normal $\sigma=0.0148$ \\
\hline
\end{tabular}


Table 4 (continued)

\begin{tabular}{lll}
\hline Parameter/product & PDF attributes & \\
\cline { 2 - 3 } & SEC fuels & SEC electricity \\
\hline Cigarettes & Triangular (5-7) & Triangular (4-5) \\
Sweet biscuits & Triangular (2700-5300) & Triangular (660-760) \\
Waffles and wafers & Triangular (2710-3300) & Triangular (630-840) \\
Flours & Triangular (200-400) & Triangular (240-540) \\
Soup and broths & Uniform (2700-5300) & Uniform (1296-2037) \\
Pasta & Triangular (2-3) & Triangular (504-940) \\
\hline
\end{tabular}

\section{References}

Blok, K., 1991. On the reduction of carbon dioxide emissions. Ph.D. Thesis, Utrecht University, The Netherlands.

Bontrider-de Steur, M., Stroeks, L., 2003. Estimating production in small enterprises. Statistics Netherlands, Division of Business statistics, The Netherlands (confidential report).

Boonekamp, P.G.M., Tinbergen, W., Vreuls, H.H.J., Wesselink, B., 2001. Protocol Monitoring Energiebesparing. Energieonderzook Centrum Nederland (ECN-C-01-129), Rijkinstituut voor volksgezonheid en milieuhygiene (RIVM 408137005). Available from: http://www.ecn.nl.

Brook, K., 2001. Temperature correction procedures to monitor changes over time of energy consumption data. Department of Trade and Industry, United Kingdom. Available from: http:// www.dti.gov.uk/energy/inform/energy_trends/tempmethod1.htm.

Carlsson-Kanyama, A., Faist, M., 2001. Energy use in the food sector: a data survey. AFR report No. 291, Environmental Strategies Research Group, Stockholm University, Sweden.

Department of Environment, 1997. Cutting energy cost in the soft drink industry. Energy consumption guide 65, Action energy, United Kingdom. Available from: www.actionenergy.org.uk.

European Commission, 2003. IPCC draft reference document on best available technologies in the food, drink and milk industry. European Community, Sevilla, Spain. Available from: http:// eippcb.jrc.es/pages/BActivities.cfm.

European Commission, 2004. Proposal for a directive of the European Parliament and of the Council on energy end-use efficiency and energy services. $\operatorname{COM}(2003)$, Brussels.

Eurostat, 2001. Report concerning national Prodcom methodologies. Eurostat.

Farla, J., 2000. Physical indicators of energy efficiency. Ph.D. Thesis, Utrecht University, The Netherlands.

Farla, J., Blok, K., 2000. The use of physical indicators for the monitoring of energy intensity developments in The Netherlands, 1980-1995. Energy 25, 609-638.

Freeman, S.L., Niefer, M.J., Roop, J.M., 1997. Measuring industrial energy intensity: practical issues and problems. Energy Policy 25, 703-714.

Gonsalves, D., 1996. Energy conservation opportunities at Tanzania Bottlers Dar es Salaam. M.Sc. Thesis, Eindhoven University of Technology, The Netherlands.

Heineken, 1999. Environmental report 1998-1999. Heineken, The Netherlands.

Hiddink, J., 2004. Personal communication. Arcadis, The Netherlands.

Hulskotte, J.H.J., Matthijsen, A.J.C.M., 1995. Produktie van suiker. Samenwekingsproject procesbeschrijvingen industrie Nederland. Rijkinstituut voor volksgezonheid en milieuhygiene (RIVM 736301110), The Netherlands.

International Energy Agency (IEA), 2003. Energy balances of OECD countries 2000-2001. OECD-IEA, Paris, France.
International Energy Agency (IEA), 2004. Oil crisis \& climate challenges: 30 Years of energy use in IEA countries. OECD-IEA, Paris, France.

Loretzon, K., Olsson, O., Reiners, V., Stadig, M., 1997. Uthållig livsmedelproduktion: en energi-och miljöstudie med inrikting not kyl, frys- ah helkonservbehandeling. Swedish Institute for Food and Bio-technology, Gothenberg, Sweden.

Meat and Livestock Commission (MLC), 1998. Economic overview of the UK beef industry. MLC, United Kingdom.

Metz, B., Ogunlade, D., Swart, R., Pan, J. (Eds.), 2001. Climate Change 2001: Mitigation. International Panel on Climate Change. University Press, Cambridge, UK.

Molinari, R., Gagliardi, R., Drioli, E., 1995. Methodology for estimating saving of primary energy with membrane operation in industrial processes. Desalination 100, 125-137.

Morgan, M.G., Henrion, M., 1990. Uncertainty. A Guide to Dealing with Uncertainty in Quantitative Risk and Policy Analysis. Cambridge University Press, New York.

Moss, R.H., Scheiner, S.H., 2000. Uncertainties in the IPCC. TAR: recommendations to lead authors for more consistent assessment and reporting. In: Pachuari, E., Taniguchi, T., Tanaka, K. (Eds.), Guidance Papers on the Cross Cutting Issues of the Third Assessment Report of the IPCC. World Meteorological Organization, Geneva, pp. 33-57.

Nanduri, M., Nyboer, J., Jaccard, M., 2002. Aggregating physical intensity indicators: results of applying the composite indicator approach to the Canadian industrial sector. Energy Policy 30, 151-163.

Nielsen, P.H., Nielsen, A.M., Weidema, B.P., Dalgaard, R., Halberg, N., 2003. LCA food data base. Available from: http://www.lcafood.dk/database.

Nederlandse Organisatie voor energie en milieu (Novem), 2001a. Voortgangsrapportage ontwikkeling energie-efficiency in de vleesindustrie over 2000. Novem (2013428/304/RG/AF/156312), The Netherlands.

Nederlandse Organisatie voor energie en milieu (Novem), 2001b. Eindrapportage ontwikkeling energie-efficiency bierbrouwerijen over de periode 1989-2000. Novem (2013580/304/RG/AF/ 156312), The Netherlands.

Nederlandse Organisatie voor energie en milieu (Novem), 2001c. Voortgangsrapportage ontwikkeling energie-efficiency in de Nederlandse cacao industrie over 2000. Novem (2014382/304/RG/ AF/156312), The Netherlands.

Nederlandse Organisatie voor energie en milieu (Novem), 2001d. Eindrapportage ontwikkeling energie-efficiency in de zuivelindustrie (NZO \& NEDSMELT) over de periode 1989-2000. Novem (2014384/304/RG/AF/156312), The Netherlands.

Nederlandse Organisatie voor energie en milieu (Novem), 2001e. Voortgangsrapportage ontwikkeling energie-efficiency in de groenten- en fruitverwerkende industrie over de periode 1989-2000. Novem (2013447/304/RG/AF/156312), The Netherlands. 
Nederlandse Organisatie voor energie en milieu (Novem), 2001f. Eindrapportage ontwikkeling energie-efficiency in de koffiebranderijen over de periode 1989-2000. Novem (2015338/304/RG/AF/ 156312), The Netherlands.

Nederlandse Organisatie voor energie en milieu (Novem), 2001g. Eindrapportage ontwikkeling energie-efficiency in de zuikerindustrie over de periode 1989-2000. Novem (2015338/304/RG/AF/ 156312), The Netherlands.

Nederlandse Organisatie voor energie en milieu (Novem), 2001h. Eindrapportage ontwikkeling energie-efficiency in de frisdrankindustrie over de periode 1989-2000. Novem (2013428/304/RG/AF/ 156312), The Netherlands.

Nederlandse Organisatie voor energie en milieu (Novem), $2001 \mathrm{i}$. Eindrapportage ontwikkeling energie-efficiency in de Nerderlandse aardappelverwerkende industrie over de periode 1989-2000. Novem (2013453/304/RG/AF/156312), The Netherlands.

Nederlandse Organisatie voor energie en milieu (Novem), 2001j. Eindrapportage ontwikkeling energie-efficiency in de margarine-, vetten- en oliënindustrie over de periode 1990-2000. Novem (2013577/304/RG/AF/156312), The Netherlands.

Phylipsen, G.J.M., Blok, K., Worrell, E., 1997. International comparisons of energy efficiency. Methodologies for the manufacturing industry. Energy Policy 25, 715-725.

Phylipsen, G.J.M., Blok, K., Worrell, E., 1998. Handbook on international comparisons of energy efficiency in the manufacturing industry. Department of Science, Technology and Society, Utrecht University, The Netherlands.

Pontoppidan, O., Hansen, P., 2000. Renere teknologi på fjerkræslagterier- Projektrapport. Miljøprojekt 573, Miljøstyrelsen, Denmark.
Available from: http://www.mst.dk/udgiv/publikationer/2000/877944-306-0/html/.

Pontoppidan, O., Hansen, P., 2001. Renere teknologi på svine- og kreaturslagterier. Arbejdsrapport 9, Miljøstyrelsen, Denmark. Available from: www.mst.dk/udgiv/publikationer/2001/87-7944$528-4 / \mathrm{html} /$.

Rijkinstituut voor volksgezonheid en milieuhygiene (RIVM), 1995. Samenwerkingproject Processbeschrijving Industrie Nederland. RIVM, RIZA, The Netherlands.

Ross, M., Feng, L., 1991. The energy efficiency of the steel industry in China. Energy 16, 833-848.

Ross, M., Hwang, R., 1992. A Model for Long Term Industrial Energy Forecasting. US Department of Energy, Washington, DC.

Schipper, L., Grubb, M., 2000. On the rebound? Feedback between energy intensities and energy uses in IEA countries. Energy Policy 28, 367-388.

Schreurs, M., 2003. Personal communication. Rendac, The Netherlands.

Suijkerbuijk, M.A.W., van Oosterhout C.J.M., Hoogenkamp A.W.H.M., 1995. Slachterijen en vleeswarenindustrie. Samenwekingsproject procesbeschrijvingen industrie Nederland. Rijkinstituut voor volksgezonheid en milieuhygiene (RIVM 773006173), The Netherlands.

World Energy Council, 2001. Energy efficiency policies and indicators. World Energy Council, United Kingdom.

Worrell, E., Price, L., Martin, N., Farla, J., Schaeffer, R., 1997. Energy intensity in the iron and steel industry: a comparison of physical and economic indicators. Energy Policy 25, 727-744. 